University of Wollongong

Research Online

Faculty of Engineering and Information

Faculty of Engineering and Information

Sciences - Papers: Part A

Sciences

$1-1-2010$

\title{
Flicker mitigation strategy for DFIGs during variable wind conditions
}

Lasantha Meegahapola

Queen's University of Belfast, lasantha.meegahapola@rmit.edu.au

Brendan Fox

Queen's University of Belfast, b.fox@ee.qub.ac.uk

Damian Flynn

University College Dublin

Follow this and additional works at: https://ro.uow.edu.au/eispapers

Part of the Engineering Commons, and the Science and Technology Studies Commons

Research Online is the open access institutional repository for the University of Wollongong. For further information contact the UOW Library: research-pubs@uow.edu.au 


\title{
Flicker mitigation strategy for DFIGs during variable wind conditions
}

\author{
Abstract \\ This paper presents a flicker mitigation scheme for the doubly-fed induction generator (DFIG) during \\ variable wind conditions. The flicker mitigation strategy was developed based on the distribution line $X / R$ \\ ratio and the active power deviation from the average active power during variable wind conditions. \\ Flicker emission was analyzed using a flicker meter based on the IEC standards. Both short-term and \\ long-term flicker severities were analyzed during the time period of study. The flicker mitigation strategy \\ was evaluated under different system conditions such as $\mathrm{X} / \mathrm{R}$ ratio, distribution line length, shortcircuit \\ capacity (SCC), and wind variability. It is shown that the proposed control scheme mitigates flicker \\ severity with different $X / R$ ratios, distribution line lengths and different wind conditions. However, the \\ proposed strategy is less effective with relatively low SCCs at the point of grid connection, due to large \\ fluctuations of the voltage at the point of grid connection.

\section{Keywords} \\ flicker, wind, variable, during, dfigs, strategy, mitigation, conditions \\ Disciplines \\ Engineering | Science and Technology Studies \\ Publication Details \\ L. Meegahapola, B. Fox \& D. Flynn, "Flicker mitigation strategy for DFIGs during variable wind conditions," \\ in IEEE PES General Meeting, PES 2010, 2010, pp. 1-8.
}




\title{
Flicker Mitigation Strategy for DFIGs during Variable Wind Conditions
}

\author{
Lasantha Meegahapola, Student Member, IEEE, Brendan Fox, and Damian Flynn, Member, IEEE
}

\begin{abstract}
This paper presents a flicker mitigation scheme for the doubly-fed induction generator (DFIG) during variable wind conditions. The flicker mitigation strategy was developed based on the distribution line $X / R$ ratio and the active power deviation from the average active power during variable wind conditions. Flicker emission was analyzed using a flicker meter based on the IEC standards. Both short-term and long-term flicker severities were analyzed during the time period of study. The flicker mitigation strategy was evaluated under different system conditions such as $\mathrm{X} / \mathrm{R}$ ratio, distribution line length, shortcircuit capacity (SCC), and wind variability. It is shown that the proposed control scheme mitigates flicker severity with different $\mathrm{X} / \mathrm{R}$ ratios, distribution line lengths and different wind conditions. However, the proposed strategy is less effective with relatively low SCCs at the point of grid connection, due to large fluctuations of the voltage at the point of grid connection.
\end{abstract}

Index Terms-DFIG, flicker mitigation, short-circuit capacity, voltage fluctuations, wind variability, $X / R$ ratio.

\section{INTRODUCTION}

$\mathrm{D}$ ISTRIBUTED wind generation is becoming increasingly popular in many parts of the world. As a consequence, it has given rise to certain issues in distribution systems, such as voltage stability, power quality, and protection [1]. The major wind generation based power quality issues are $3 \mathrm{p} / 2 \mathrm{p}$ power oscillations due to the tower shadow effect [2-3] (especially with fixed-speed wind turbines), voltage fluctuations/flicker due to variable wind conditions [4,7], and harmonics due to power electronics components [8-9] in wind generation systems (doubly-fed induction generator (DFIG) and direct-drive synchronous generator (DDSG) wind generators). The main emphasis of this paper is on mitigation of flicker using an additional reactive power control scheme for the DFIG during variable wind conditions.

The phenomenon of flickering of light sources has been known since the development of distribution networks. Flicker is defined as the human perception (visual sensation) of annoyance due to the fluctuation of luminous flux from a light source [10-11]. Typically, flickering is identified as a

This work was funded by a Charles Parsons Energy Research Award from the Department of Communications, Energy and Natural Resources, Republic of Ireland.

Lasantha Meegahapola, and Brendan Fox are with the Electric Power and Energy Systems Research Group, Ashby Building, The Queen's University of Belfast, Stranmillis Road, Belfast, BT9 5AH, Northern Ireland, UK.

Damian Flynn is with Electricity Research Centre, University College Dublin, Belfield, Dublin 4.

(e-mail addresses: lmeegahapola01@qub.ac.uk, b.fox@ee.qub.ac.uk, and damian.flynn@ucd.ie) consequence of nonlinear loads connected to power distribution systems. As an example, arc furnaces, dischargetype light sources, and induction motors are examples of loads with nonlinear characteristics. Due to the large scale integration of wind generators in power distribution systems, flicker becomes a significantly important power quality issue during variable wind conditions.

In the published literature, several studies can be identified on flicker measurement, analysis and mitigation for wind generation systems [4-7]. The flicker emission of the fixed-speed wind generator is mainly caused by the variable wind speed and the tower shadow effect [4]. However, for a variable speed wind generator flicker is caused by the variable wind speed. The study conducted by Larson analyzed the effect of flicker emission for a fixed-speed wind generator [4]. In ref [5] the authors have analyzed various factors affecting the flicker emission of wind farms such as mean wind speed, turbulence intensity, short-circuit capacity (SCC) and grid impedance angle (X/R ratio) using sensitivity analysis. In addition, a number of studies can be identified which have analyzed flicker emission from different perspectives. As an example, in ref [6] the authors have analyzed the flicker emission of variable speed permanent magnet synchronous generators and the impact of various system parameters.

A number of studies have outlined flicker mitigation strategies for wind farms [7,12]. In ref [7] the authors have proposed a control scheme for DFIGs, based on the grid impedance and power factor angle control using the grid-side converter (GSC) of the DFIG. In that scheme, the voltage fluctuation during variable speed operation was derived as a function of the grid impedance angle and the power factor angle. The control philosophy was to maintain the difference between the grid impedance and the power factor angle close to 90 degrees. However, this control strategy suffers from a deteriorated power factor and voltage stability issues at the point of grid connection, due to large changes in reactive power during variable wind conditions. In addition, certain authors have proposed flicker mitigation strategies using static-synchronous compensator (STATCOM) based solutions [12], however such solutions are unlikely to be financially viable for distributed generation applications.

This study implemented a rotor-side converter (RSC) based reactive power control scheme for flicker reduction during variable wind conditions. The DFIG based reactive power control schemes are utilized for power factor control, voltage control, voltage stability improvement [13], and system loss reduction [14]. The time scale of those control strategies are vary from milliseconds to hours based on the reactive power support required for particular application. In this study, a me- 
dium-term reactive power control scheme has been proposed for flicker mitigation.

This paper is organized as follows. Flicker theory and measurement standards are outlined in Section II. Section III focuses on DFIG modeling and control with special emphasis on (RSC) control. Section IV examines the flicker emission during variable wind conditions, which illustrates the flicker severity from a wind farm operating under variable wind conditions. The proposed control scheme and its performance are discussed in Section V. Section VI analyzes the performance of the proposed strategy under different system conditions. Finally conclusions and future work are presented in Section VII.

\section{FLICKER THEORY AND MEASUREMENT}

Voltage variations can be classified into several types, such as voltage dips, swells, collapse and fluctuations. The first three issues are directly associated with power system protection and stability. However, voltage fluctuations are identified as a power quality issue, which is defined in the range of $\pm 10 \%$ of the nominal system voltage [11]. Flicker is identified as a type of voltage fluctuation with associated physiological and pathological components such as duress, and tiredness, due to the fluctuation of luminous flux during voltage fluctuations.

Flicker was initially measured considering the variations in the luminous flux of a light source. Later measurement models considered the actual human perception of annoyance caused by fluctuations in luminous flux, and researchers have modeled the visual perception, especially the response of the human eye as a band-pass filter. Early human perception based models were developed considering a $60 \mathrm{~W}, 230 \mathrm{~V}$ tungsten bulb, which was the most commonly used light source in Europe at that time [11]. At present, the flicker measurement is conducted using electronic equipment, which characterize the light source and human perception using digital/analog filters. Fig. 1 illustrates a functional block diagram of a flicker meter.

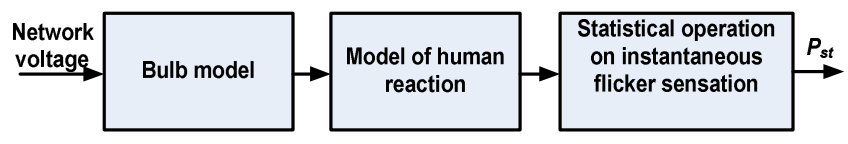

Fig. 1. Flicker measurement model.

The input to this instrument is the network voltage, which is fed into the bulb model to generate the typical characteristics of a light bulb for network voltage fluctuations. The output signal from the bulb model is then used to derive the human eye reaction based on a human eye and brain model. The human eye and brain model is developed as a band-pass filter. The output of this model is known as the instantaneous flicker severity, which is then used to derive the statistical measure of flicker severity known as short-term flicker severity $\left(P_{s t}\right)[11]$. This is measured over a $10 \mathrm{~min}$. period and calculated based on the cumulative probability function. The long-term flicker severity $\left(P_{l t}\right)$ is a rolling average of $P_{s t}$ measured over a two hour time frame. In this study, a flicker meter has been implemented using MATLAB according to IEC 61000-4-15 standard [15] to measure the short-term flicker severity for the studied test system.

\section{DFIG MODELING AND CONTROL}

The DFIG is essentially a wound rotor induction generator (WRIG), with a rotor coupled voltage source converter, which is commonly known as the rotor-side converter (RSC). The RSC independently controls the active power and reactive power, and the control strategy is typically based on vector control techniques in the $d q$-reference frame. The grid-side converter (GSC) maintains the DC link voltage constant and operates at unity power factor. The rotor exports active power above synchronous speed, and absorbs active power below synchronous speed. Crowbar protection is used to protect the RSC from high current transients during transient disturbances [16]. A schematic diagram of a DFIG is shown in Fig. 2.



Fig. 2. Schematic diagram of DFIG.

Since the flicker control strategy is implemented at the RSC, the main focus here is placed on the RSC control scheme. The RSC control model basically consists of two control loops, i.e. a fast current control loop and a slow power control loop, as shown in Fig. 3.

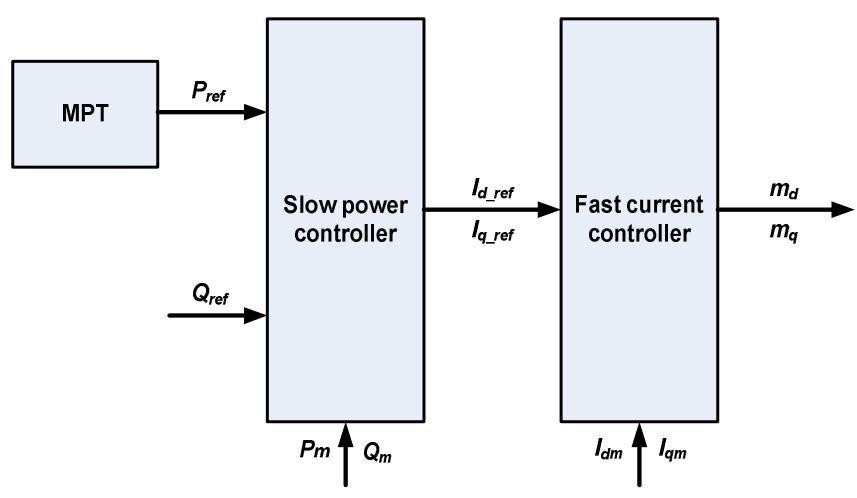

Fig. 3. DFIG RSC model.

Where $P_{\text {ref }}, Q_{\text {ref }}, P_{m}, Q_{m}, I_{d_{-} r e f}, I_{q_{-} r e f}, I_{d m}, I_{q m}, m_{d}$, and $m_{q}$ denote active power reference, reactive power reference, measured active power, measured reactive power, d-axis current reference, q-axis current reference, d-axis current, qaxis current, d-axis modulation index, and q-axis modulation index, respectively. 
The fast control loop determines the phasor compensation and regulates the rotor current, as specified by the slow controller using the fast current control. The outputs of the fast controller are the respective modulation indexes for the $d$ - and $q$-axis rotor voltage. The slow controller generates the current references for the fast controller, considering the active power and reactive power reference values. Typically, the active power reference is generated by the maximum power tracking (MPT) characteristic of the wind generator, while reactive power reference is kept at zero unless there is a reactive power or voltage control scheme implemented using the DFIG [14]. However, the DFIG maintains its reactive power limits within the grid code standards under all operating conditions.

\section{FLICKER EMISSION DURING VARIABLE WIND CONDITIONS}

Variable wind conditions cause fluctuations in power generation at wind farms, and ultimately cause voltage variations at the point of grid connection. This phenomenon can be understood by considering a generator feeding active and reactive power to an external grid via a distribution line (see Fig. 4).


(b)

Fig. 4. (a) Single machine system (b) Phasor diagram.

Where $P_{g}, Q_{g}, V_{g}, V_{s}, I_{g}, R, X$, and $\theta$ represent active power generation, reactive power generation, generator end voltage, grid voltage, line current, line resistance, line reactance, and power factor at grid, respectively. From Fig. 4, the voltage difference between the generator and grid can be approximated as follows.

$$
\begin{aligned}
& V_{g}-V_{s}=\Delta V=Z I_{g}=(R+\mathrm{j} X)\left(\frac{P_{g}-j Q_{g}}{V_{g}}\right) ; Z=\sqrt{R^{2}+X^{2}} \\
& \Delta V=\frac{R P_{g}+X Q_{g}}{V_{g}}+\mathrm{j} \frac{X P_{g}-R Q_{g}}{V_{g}} \\
& \Delta V=\Delta V_{p}+\mathrm{j} \Delta V_{q}
\end{aligned}
$$

If it is assumed that the imaginary component in (1) is negligibly small compared to the real component, then the voltage difference simplifies to:
$\Delta V \approx \frac{R P+X Q}{V_{g}}$

According to (2), both the active and reactive power cause a voltage difference between the two ends of the distribution line. If the generator is a DFIG, the reactive power is typically maintained at zero (unity power factor) unless additional voltage or reactive power support is requested. Therefore, during variable wind conditions the DFIG reactive power can be considered as zero, and hence the active power is the only determinant of the voltage difference between the two ends of the distribution line. The test system shown in Fig. 5 was formulated in DIgSILENT to analyze the voltage fluctuations during variable wind conditions.

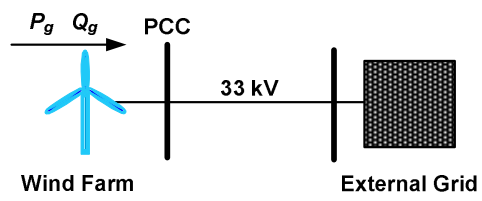

Fig. 5. Test system.

The wind farm has a $100 \mathrm{MW}(20 \times 5 \mathrm{MW})$ installed capacity, and is operated at unity power factor. The wind speed was varied between 11-13 $\mathrm{ms}^{-1}$ during a 6 hour period. The wind time series was produced based on weibull probability density function [17]. The wind farm was connected via a distribution line $(\mathrm{X} / \mathrm{R}=1)$ to an external system having $500 \mathrm{MVA}$ SCC at the point of grid connection. The wind speed, active power, reactive power, and voltage at the point of grid connection are illustrated in Fig. 6.

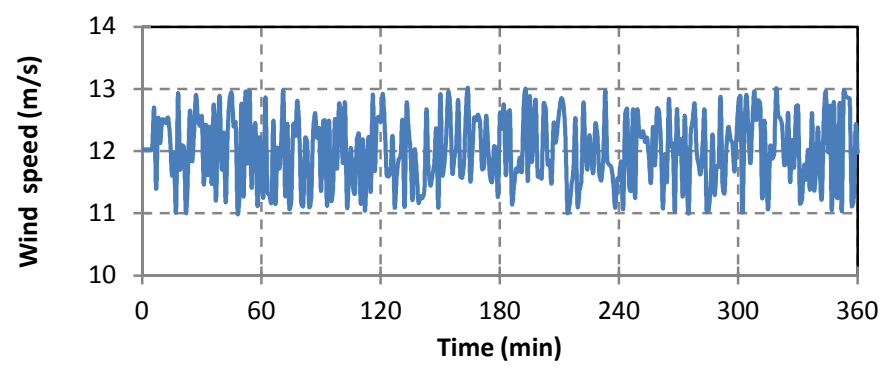

(a)

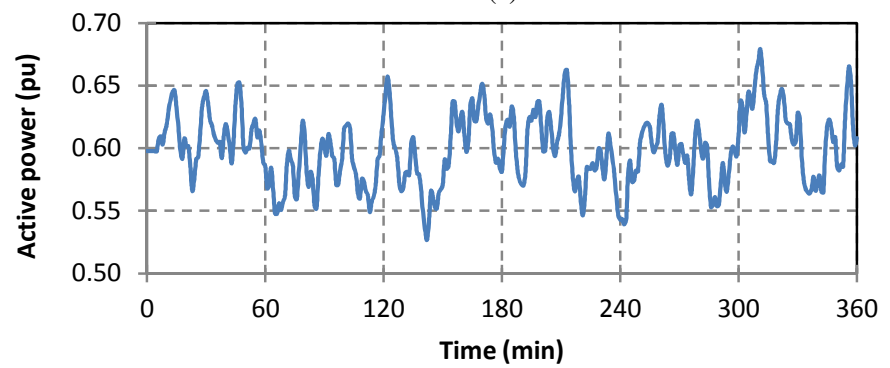

(b)

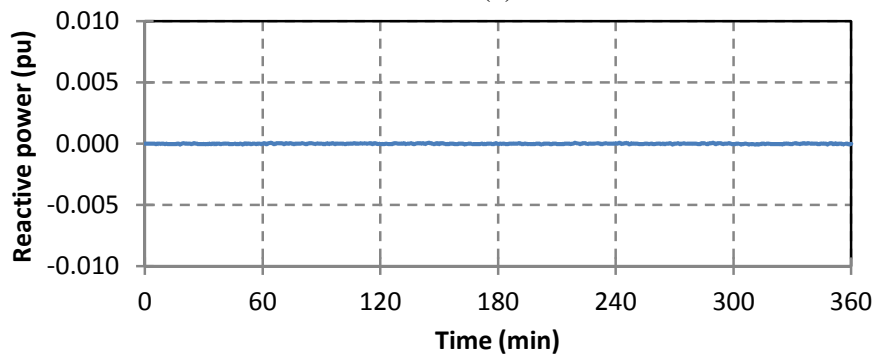

(c) 




(d)

Fig. 6. Wind farm performance during variable wind condition (a) Wind speed (b) Active power (c) Reactive power (d) Voltage.

According to Fig. 6, the wind farm active power output varies between 0.53 pu to $0.68 \mathrm{pu}$, and ultimately causes voltage variations between $0.991 \mathrm{pu}$ and $1.011 \mathrm{pu}$ during the 6 hour period. This represents a $2 \%$ variation compared to the nominal system voltage. The average long-term flicker severity $\left(P_{l t}\right)$ for the 6 hour period is 1.24 , which represents a high value compared to the long-term flicker emission utility standard for wind farms $\left(P_{l t}<0.50\right.$ for $\left.10-20 \mathrm{kV}\right)$ [18], and for a typical low voltage distribution system $\left(P_{l t}<0.65\right)$ [11]. Since the reactive power generation is zero, the imaginary component of the voltage in (1) becomes significant, hence the approximation in (2), may be unacceptable during such circumstances.

\section{DFIG CONTROL STRATEGY FOR FLICKER MitiGATION}

\section{A. Control Strategy}

The DFIG flicker mitigation strategy was developed based on the approximate relation for the voltage difference in (2). According to (2), if the voltage difference is zero $(\Delta V=0)$, then the equation (2) simplifies to:

$$
P=-\left(\frac{X}{R}\right) Q
$$

Conversely, if a $\Delta P$ power variation causes a voltage difference, $\Delta Q$ reactive power response could mitigate the impact according to the following relation.

$\Delta Q=-\left(\frac{R}{X}\right) \Delta P$

According to (3), the reactive power response is based on the $\mathrm{R} / \mathrm{X}$ ratio. However, due to the internal gains of a DFIG, and approximations made during the derivation of (2)-(3) this ratio may differ from the theoretical value. In general, the required reactive power compensation can be expressed as:

$\Delta Q=K_{R X} \Delta P$

The value of $K_{R X}$ can be approximated based on the actual $\mathrm{X} / \mathrm{R}$ ratio, and the internal gains of the reactive power control loops of the DFIG. The functional block diagram of the RSC reactive power control scheme and flicker control scheme are illustrated in Fig. 7. The flicker control scheme was implemented as part of the slow controller of the RSC. The variation in active power is determined based on the moving average of the active power calculated over a time period.
Then the deviation is integrated to derive the cumulative active power difference for a particular time frame before multiplication by the flicker control gain $\left(K_{R X}\right)$.

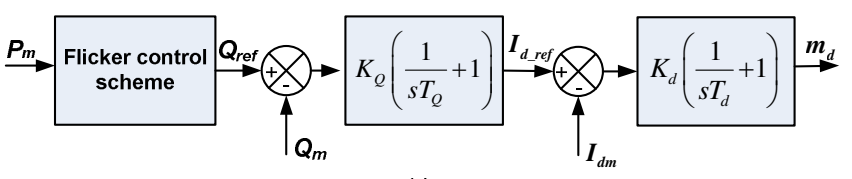

(a)

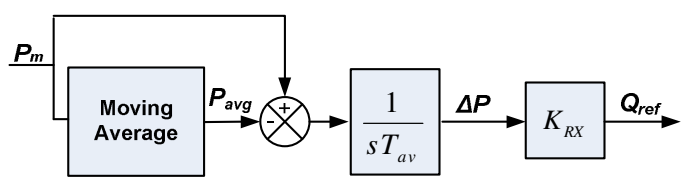

(b)

Fig. 7. (a) Reactive power control scheme of RSC (b) Flicker control scheme.

Where $K_{Q}, K_{d}, T_{Q}, T_{d}, T_{a v}$ and $\Delta P$ denote reactive power control gain, d-axis current control gain, reactive power time constant, d-axis current time constant, net active power integrator time constant, and net active power difference, respectively.

The constants for reactive power $\left(T_{Q}\right)$ controller and d-axis current $\left(T_{d}\right)$ controller are $10 \mathrm{~ms}$ to $100 \mathrm{~ms}$ respectively. The integrator time constant is taken as $60 \mathrm{~s}$ to avoid rapid change in reactive power reference and smoothes the reactive power response. The flicker control gain can be approximated by linearizing the transfer functions as follows:

$K_{R X}=\left[\frac{(R / X)}{\left(\frac{K_{d}}{T_{d}}+K_{d}\right)\left(\frac{K_{Q}}{T_{Q}}+K_{Q}\right)}\right]$

However, the flicker control gain has to be properly tuned for a wind farm installed at a particular location in the network. Further, value of $K_{R X}$ may slightly change based on the wind profile, since the active power deviation is influenced by the wind speed. This is because the DFIG follows different power vs. speed [19] characteristics based on the wind speed at a particular instance. Therefore lookup table can be used to obtain the required control gain for particular wind profile.

\section{B. Performance of the Flicker Mitigation Scheme}

The proposed control scheme was implemented on the test system illustrated in Fig. 5 and the voltage variation was analyzed over a 6 hour period.

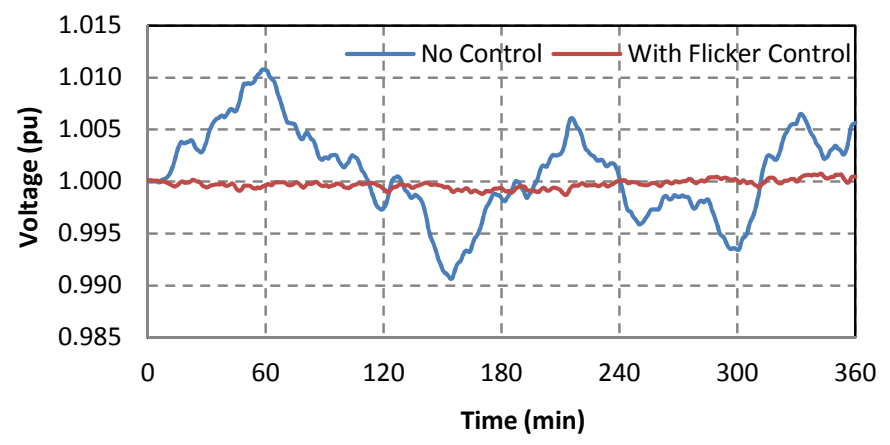

(a) 


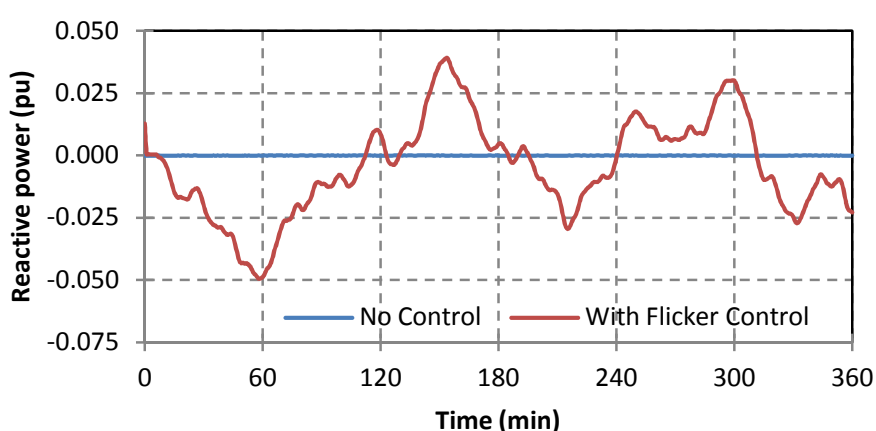

(b)

Fig. 8. Wind farm performance comparison after implementing flicker mitigation strategy (a) Voltage (b) Reactive power.

Fig. 8 illustrates the comparison between normal operation and flicker controlled operation of the DFIG. It can be seen that the voltage fluctuations are significantly reduced after implementing the flicker mitigation scheme. As an example, the maximum voltage fluctuation during the 6 hour period has reduced from $2 \%$ to $0.2 \%$, which is a significant reduction in voltage fluctuation at the point of grid connection. This is because the proposed control scheme has controlled the reactive power of the DFIG in response to the active power variation of the wind generator. Fig. 9 illustrates the variation in $P_{s t}$ over a 6 hour period.

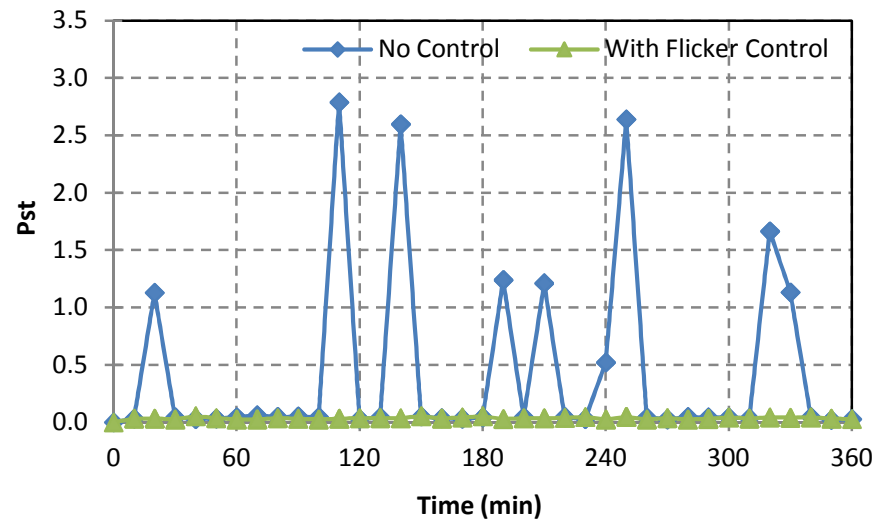

Fig. 9. Comparison of short-term flicker severity.

It can be seen from Fig. 9 that the proposed scheme has reduced the short-term flicker emission during the period of high wind variability, and the short-term flicker severity is less than the minimum value stated by the utility standards $\left(P_{s t}<0.35\right)$ [20]. The wind farm has an average long-term flicker severity $P_{l t}$ of 1.24 during normal operation, which is reduced to 0.038 after implementing the flicker mitigation strategy.

\section{RESULTS AND DISCUSSION}

The proposed strategy was analyzed under different conditions, such as distribution line $\mathrm{X} / \mathrm{R}$ ratio (grid impedance angle), distribution line length, short-circuit capacity (SCC) at the point of grid connection, and wind variability. The test system illustrated in Fig. 5 was adopted to analyze the effect of the above factors on mitigating voltage fluctuations during variable wind conditions.

\section{A. Impact of $X / R$ ratio}

The distribution line $\mathrm{X} / \mathrm{R}$ ratio was varied while maintaining the line impedance at a constant value. The wind farm was connected to an external system having a 500 MVA SCC, and the wind speed variation was $11-13 \mathrm{~ms}^{-1}$. The wind farm was operated at unity power factor (on average), and the variation in voltage for different X/R ratios is illustrated in Fig. 10.

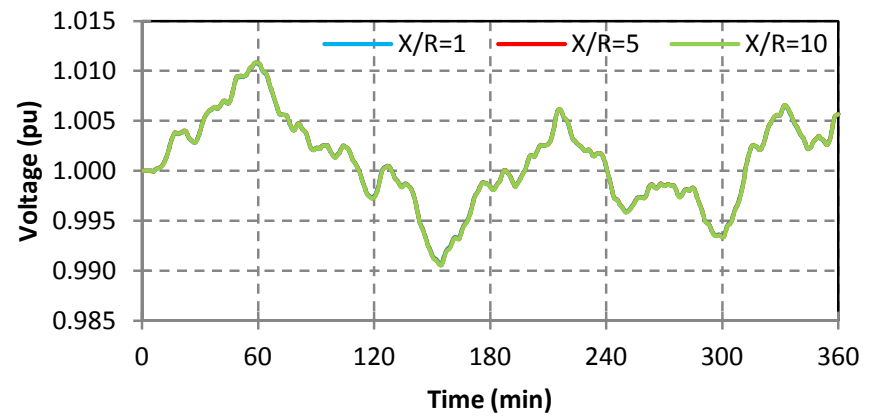

(a)



(b)

Fig. 10. Flicker mitigation strategy performance with different $\mathrm{X} / \mathrm{R}$ ratios (a) Before implementation (b) After implementation.

It can be seen from Fig. 10 that the voltage fluctuations are largely unaffected by the distribution line $\mathrm{X} / \mathrm{R}$ ratio. In addition, the average voltage is also not affected, since the line impedance was maintained constant in all scenarios. However, the flicker control gain $\left(K_{R X}\right)$ was adjusted based on the internal control gains of the DFIG and the X/R ratio. Ultimately, the proposed flicker mitigation scheme has shown optimistic results under different $\mathrm{X} / \mathrm{R}$ ratios.

\section{B. Impact of SCC at point of grid connection}

The short-circuit capacity is a relative indicator of the voltage stiffness of a particular node in the system. The higher the SCC, the higher the voltage stiffness of that node, and hence the voltage variation should be relatively low during variable power operation. Fig. 11 illustrates the voltage variation of wind farms for different SCCs (between $250 \mathrm{MVA}$ and 1000 MVA) at the point of grid connection. The line $\mathrm{X} / \mathrm{R}$ ratio was maintained at 1 , and the wind speed variation was $11-13 \mathrm{~ms}^{-1}$.

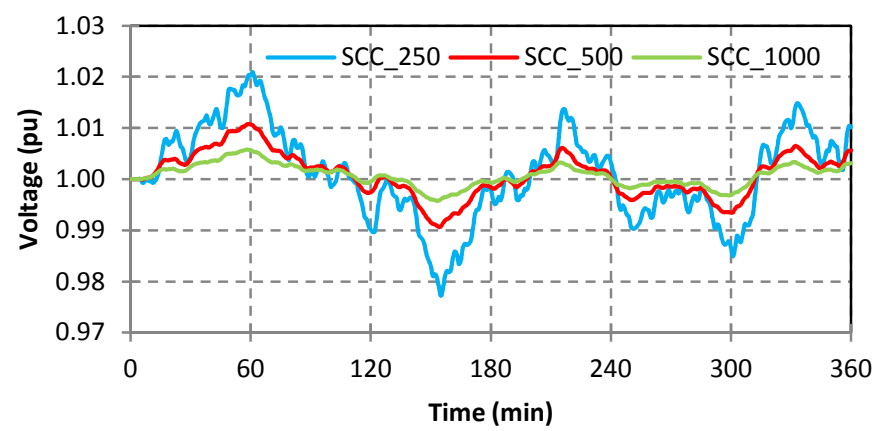

(a) 


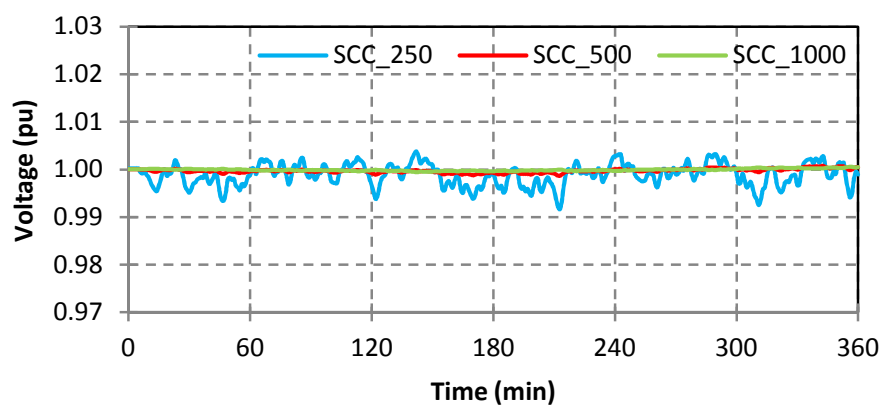

(b)

Fig. 11. Flicker mitigation strategy performance with different SCCs (a) Before implementation (b) After implementation.

It can be seen from Fig. 11 that when the SCC decreases that the voltage fluctuations are exacerbated, and ultimately the effectiveness of the proposed strategy has reduced. As an example, at 1000 MVA SCC, the maximum voltage fluctuation is $2 \%$, which increases to $4.4 \%$ when the SCC reduces to 250 MVA. When the flicker control scheme was implemented the voltage fluctuation reduced to $0.11 \%$ at 1000 MVA SCC. However, at $250 \mathrm{MVA}$ it has only reduced to $1.21 \%$, which is a comparatively low reduction in voltage fluctuation. Table I illustrates the long-term flicker severity measured for different time periods.

TABLE I

LONG-TERM FLICKER SEVERITY WITH DIFFERENT SCC

\begin{tabular}{c|c|l|c|l|c|l}
\hline \hline & \multicolumn{2}{|c|}{$250 \mathrm{MVA}$} & \multicolumn{2}{c|}{$500 \mathrm{MVA}$} & \multicolumn{2}{c}{$1000 \mathrm{MVA}$} \\
\hline $\begin{array}{c}\text { Time } \\
\text { (hrs) }\end{array}$ & $\begin{array}{c}\text { No } \\
\text { control }\end{array}$ & $\begin{array}{l}\text { Flicker } \\
\text { control }\end{array}$ & $\begin{array}{c}\text { No } \\
\text { control }\end{array}$ & $\begin{array}{l}\text { Flicker } \\
\text { control }\end{array}$ & $\begin{array}{c}\text { No } \\
\text { control }\end{array}$ & $\begin{array}{c}\text { Flicker } \\
\text { control }\end{array}$ \\
\hline $0-2$ & 1.682 & 1.678 & 1.245 & 0.035 & 0.991 & 0.028 \\
\hline $2-4$ & 1.546 & 1.277 & 1.212 & 0.041 & 1.037 & 0.030 \\
\hline $4-6$ & 1.748 & 1.160 & 1.269 & 0.038 & 1.355 & 0.031 \\
\hline \hline
\end{tabular}

The long-term flicker severity has significantly reduced when the SCCs are at 500 MVA and 1000 MVA. However, at 250 MVA which represents the flicker reduction is comparatively low and the values obtained are beyond the flicker standards. This confirms the fact that additional flicker control conditions are needed when the SCC is low at the point of grid connection.

\section{Distribution line length}

Distribution line length affects the impedance of the distribution line. Therefore, the distribution line impedance affects the voltage difference between the two ends of the line. This has been analyzed for a range of different distribution line lengths, assuming a $500 \mathrm{MVA}$ SCC and $11-13 \mathrm{~ms}^{-1}$ wind variability.

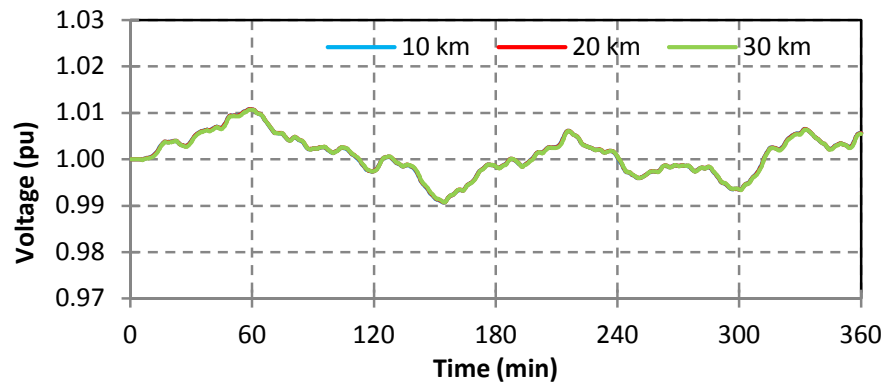

(a)

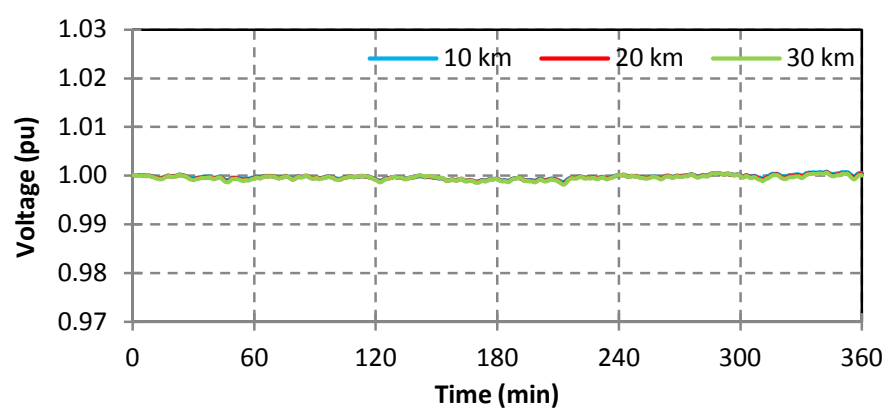

(b)

Fig. 12. Flicker mitigation strategy performance with different distribution line lengths (a) Before implementation (b) After implementation.

It can be seen that the impact on voltage difference due to a variation in distribution line length is negligible, since the impedance change due to a change in distribution line length $(0.014 \Omega$ to $0.0424 \Omega)$ is comparatively small compared to the power variability at the wind farm. Therefore, distribution line length has minimal impact on the flicker control strategy for a DFIG. However, a distribution line with high impedance may cause a more noticeable change in voltage at the point of grid connection to the wind farm.

\section{Wind Variability}

The mean wind speed and wind turbulence intensity are important factors which affect flicker emission from wind farms. This has been analyzed for two different wind profiles having different mean wind speeds and turbulence intensities. The same test system was adopted with the 500 MVA SCC and a $\mathrm{X} / \mathrm{R}$ ratio of 1 . In addition, the wind farm was operated at unity power factor. The turbulence intensity $(I)$ is calculated as:

$I=\frac{\sigma_{u}}{\bar{u}}$

Where, $\bar{u}$ and $\sigma_{u}$ denote the mean wind speed and standard deviation, respectively. This is measured over a $10 \mathrm{~min}$. time period. The mean wind speed and wind turbulence intensities for the two wind profiles are shown in Table II.

TABLE II

WIND PROFILE CHARACTERISTICS

\begin{tabular}{c|c|c}
\hline \hline Wind profile & $\begin{array}{c}\text { Mean wind speed } \\
\left(\mathrm{ms}^{-1}\right)\end{array}$ & $\begin{array}{c}\text { Avg. turbulence } \\
\text { intensity }\end{array}$ \\
\hline $11-13 \mathrm{~ms}^{-1}$ & 12.006 & 0.048 \\
\hline $8-10 \mathrm{~ms}^{-1}$ & 9.036 & 0.062 \\
\hline \hline
\end{tabular}

The two wind profiles have different wind turbulence intensities, hence the grid voltage response will be different. The voltage variations for the two wind profiles after implementing the control scheme are illustrated in Fig. 13.



(a) 


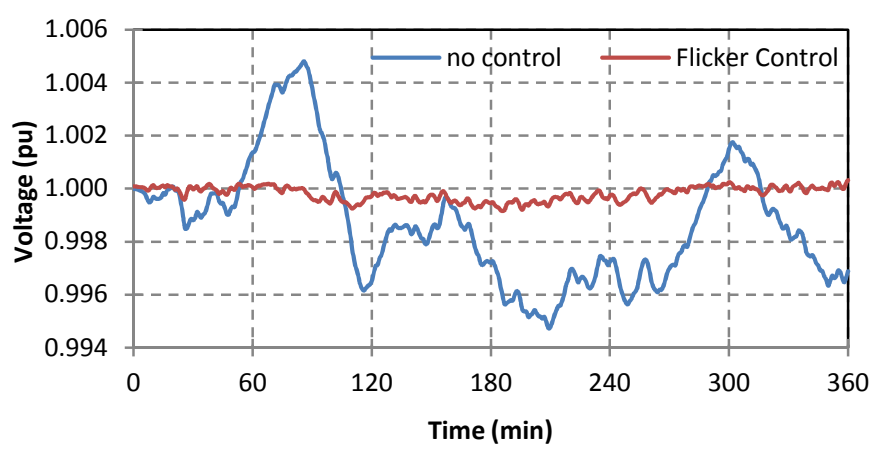

(b)

Fig. 13. Flicker mitigation strategy performance with different wind profiles (a) Wind profile $11-13 \mathrm{~ms}^{-1}$ (b) Wind profile $8-10 \mathrm{~ms}^{-1}$.

For the case of the 11-13 $\mathrm{ms}^{-1}$ wind profile the voltage fluctuation was $2 \%$, while for the $8-10 \mathrm{~ms}^{-1}$ wind profile it was $1 \%$. After implementing the control scheme the voltage fluctuation was reduced to $0.2 \%$ with the $11-13 \mathrm{~ms}^{-1}$ wind profile, while with the $8-10 \mathrm{~ms}^{-1}$ wind profile it was reduced to $0.12 \%$. The wind profile with the higher wind turbulence intensity has shown a reduction in voltage fluctuation compared to the wind profile with low wind turbulence. Furthermore, analysis has also been carried out in terms of the long-term flicker emission of the strategy, and the results are illustrated in Table III.

TABLE III

LONG-TERM FLICKER SEVERITY

\begin{tabular}{c|c|c|c|c}
\hline \hline & \multicolumn{2}{|c|}{$11-13 \mathrm{~ms}^{-1}$} & \multicolumn{2}{c}{$8-10 \mathrm{~ms}^{-1}$} \\
\hline Time (hrs) & No control & $\begin{array}{c}\text { Flicker } \\
\text { control }\end{array}$ & No control & $\begin{array}{c}\text { Flicker } \\
\text { control }\end{array}$ \\
\hline $0-2$ & 1.245 & 0.035 & 0.84 & 0.030 \\
\hline $2-4$ & 1.212 & 0.041 & 0.94 & 0.027 \\
\hline $4-6$ & 1.269 & 0.038 & 0.20 & 0.029 \\
\hline \hline
\end{tabular}

The wind profile with high turbulence intensity presents reduced flicker emission due to its low mean wind speed, since a lower mean wind speed causes much reduced power fluctuations compared to the higher mean wind speed. However, both cases show a reduction in long-term flicker emission, and both are within the flicker emission standard for wind farms.

\section{CONCLUSIONS}

A control scheme based on the distribution line $\mathrm{X} / \mathrm{R}$ ratio and active power variation was proposed for flicker mitigation of wind farms during variable wind conditions. The proposed control scheme has shown significant reduction in flickering and voltage fluctuations during variable wind conditions. Flicker severity was measured using both short-term flicker severity and long-term flicker severity. After implementing the flicker mitigation strategy a significant reduction in both metrics has been shown. Further analysis was carried out on the impact of varying distribution line $\mathrm{X} / \mathrm{R}$ ratio, distribution line length, SCC, and wind variability. More promising results are achieved with different $\mathrm{X} / \mathrm{R}$ ratios and distribution line lengths. However with low SCCs the performance of the control strategy is noticeably reduced due to low voltage stiffness at the point of grid connection. The flicker mitigation strategy has effectively reduced flicker emission with wind profiles possessing different characteristics. However, an increase in wind turbulence limits the decrease in flicker emission, although flicker is within the standard for wind farms.

Further studies are proposed with different operating power factors (e.g. 0.95 lag, 0.95 lead) and control schemes (i.e. voltage control and power factor control at PCC) for the wind farms by using the data from an actual DFIG wind farm. In addition, it is essential to analyze the flicker mitigation scheme with multiple wind farms connected to a common distribution system feeder together with the load dynamics in the network.

\section{ACKNOWLEDGMENT}

The authors would like to thank The Department of Communications, Energy and Natural Resources, Republic of Ireland for funding this research under the strategy for Science, Technology and Innovation (2006-2013).

\section{APPENDIX}

5 MW DFIG parameters: rated stator voltage: $3.3 \mathrm{kV}$; rated rotor voltage: $1939 \mathrm{~V}$; rated mechanical power: $5000 \mathrm{~kW}$; rated speed: $1800 \mathrm{rpm}$; rated frequency: $50 \mathrm{~Hz}$; no. pole pairs: 2; stator resistance: $0.00298 \mathrm{pu}$; stator reactance: $0.125 \mathrm{pu}$; rotor reactance: $0.05 \mathrm{pu}$; rotor resistance: $0.004 \mathrm{pu}$; generator inertia: $101.72 \mathrm{kgm}^{2}$; turbine inertia: $6,100,000 \mathrm{kgm}^{2}$; shaft stiffness: $83,000,000 \mathrm{Nm} / \mathrm{rad}$.

\section{REFERENCES}

[1] B. Fox, D. Flynn, L. Bryans, N. Jenkins, D. Milborrow, M. O' Malley, and R. Watson, "Wind power integration: connection and system operation aspects," IEE Power and Energy Series 50, 2007.

[2] S. Brownlees, D. Flynn, B. Fox, and T. Littler, "The impact of wind farm power oscillations on the Irish power system," IEEE PowerTech 2007, Lausanne, Switzerland, Jul. 2007.

[3] D. McSwiggan, T. Littler, D.J. Morrow, and J. Kennedy, "A study of tower shadow effect on fixed-speed wind turbines," UPEC 2008, Padova, Italy, Sep. 2008.

[4] A. Larsson, "Flicker emission of wind turbines during continuous operation," IEEE Trans. Energy Conv., vol. 17, no. 1, pp. 114-118, Mar. 2002.

[5] M. P. Papadopoulos, S. A. Papathanassiou, S. T. Tentzerakis, and N. G. Boulaxis, "Investigation of the flicker emission by grid connected wind turbines," 8th Int. Conf. Harmonics Quality of Power, Athens, Greece, Oct. 1998.

[6] W. Hu, Z. Chen, Y. Wang, and Z. Wang, "Flicker study on variable speed wind turbines with permanent magnet synchronous generator," EPE-PEMC 2008, Poznan, Poland, Sep. 2008.

[7] T. Sun, Z. Chen, and F. Blaabjerg, "Flicker study on variable speed wind turbines with doubly fed induction generators," IEEE Trans. Energy Conv., vol. 20, no. 4, pp. 896-905, Dec. 2005.

[8] S. Tentzerakis, N. Paraskevopoulou, S. Papathanassiou, and P. Papadopoulos, "Measurement of wind farm harmonic emissions," IEEEPESC 2008, Sydney, Australia, Jun. 2008.

[9] T.M.H. Nicky, K. Tan, and S. Islam, "Mitigation of harmonics in wind turbine driven variable speed permanent magnet synchronous generators," IPEC 2005, Dec. 2005.

[10] Copper Development Association, "Power quality application guide, voltage disturbances-flicker," Apr. 2006.

[11] Copper Development Association, "Power quality application guide, voltage disturbances-flicker measurement," Oct. 2005.

[12] C. Carrillo, F. Pérez-Sabín, E. Díaz-Dorado, and J. Cidrás, "Flicker mitigation and voltage sag ride through of a wind turbine using an STATCOM," EWEC 2009, Marseille, France, Mar. 2009.

[13] L.G. Meegahapola, D. Flynn, J. Kennedy, and T. Littler, "Active use of DFIG based wind farms for transient stability improvement during grid disturbances," IEEE PES GM 2009, Calgary, Canada, Jul. 2009. 
[14] L.G. Meegahapola, S. Durairaj, D. Flynn, and B. Fox, "Coordinated utilisation of wind farm reactive power capability for system loss optimisation," European Trans. on Electrical Power, 2009. (in press)

[15] IEC 61000-4-15:1997, Electromagnetic Compatibility (EMC) - Part 4: Testing and Measurement Techniques-Section 15: Flicker meter Functional and Design Specifications.

[16] A.H. Kasem, E.F. El-Saadany, and H.H. El-Tamaly, "An improved fault-ride through strategy for doubly-fed induction generator based wind turbines," IET RPG, vol. 2, no. 4, pp. 201-214, 2008.

[17] J.V. Seguro, and T.W. Lambert, "Modern estimation of the parameters of the Weibull wind speed distribution for wind energy analysis," Journal of Wind Engineering and Industrial Aerodynamics, vol. 85, no. 1, pp. 75-84, Mar. 2000.

[18] Technical Regulations TF 3.2.6, "Wind turbines connected to grids with voltage below $100 \mathrm{kV}$ - technical regulations for the properties and the control of wind turbines," Eltra and Ekraft systems, 2004.

[19] A.D. Hansen, C. Jauch, P. Sorensen, F. Iov, and F. Blaabjerg, "Dynamic wind turbine models in power system simulation tool DIgSILENT," Ris $\phi$ report Ris $\phi-R-1400(E N)$, Denmark, 2004.

[20] Research Institute for Danish Electric Utilities (DEFU), "Connection of wind turbines to low and medium voltage networks," $2^{\text {nd }}$ ed., Oct. 1998.

\section{BIOGRAPHIES}

Lasantha Meegahapola (S'06) was born in Colombo, Sri Lanka in $1982 . \mathrm{He}$ received a $1^{\text {st }}$ class BSc. Eng. Honors degree from University of Moratuwa, Sri Lanka in 2006. He is currently pursuing a PhD at The Queen's University of Belfast, UK. His research interests include renewable power generation, power system stability, and intelligent approaches in power systems.

Brendan Fox graduated with a BSc and a PhD from The Queen's University of Belfast (QUB) in 1966 and 1969. Following a period in the electricity supply industry, he joined the Ulster Polytechnic in 1972 and QUB in 1980, where he is currently a Professor in Electrical Engineering. His teaching and research interests are in power system engineering, with a particular interest in the operational integration of renewable energy on a large scale.

Damian Flynn (M'96) is a senior lecturer in power engineering at University College Dublin. His research interests involve an investigation of the effects of embedded generation sources, especially renewables, on the operation of power systems. He is also interested in advanced modeling and control techniques applied to power plant. $\mathrm{He}$ is a member of the IEEE. 